\title{
International Variation in Ageing and Economic Dependency: A Cohort Perspective
}

\author{
Elke Loichinger, Vegard Skirbekk
}

\begin{abstract}
Within this analysis of demographic and economic dependency ratios for 45 countries around the world, we reiterate the importance of age- and gender-specific employment levels as well as their determinants when discussing the economic challenges associated with population ageing. Building upon existing research on economic dependency, we portray and discuss cohort variation in employment and its possible effect on the challenges of population ageing, focusing on the implications of high youth unemployment, the role of changes in female employment and the evolution of retirement patterns across cohorts. The insights from our analysis reaffirm findings elsewhere that younger populations may not be as well off in the light of demographic change as an analysis of their demographic structure alone would suggest and stress the importance of considering the cohort dimension of employment in this discussion.
\end{abstract}

Keywords: Dependency $\cdot$ Population ageing $\cdot$ Economic dependency $\cdot$ Cohorts

\section{Introduction}

All nations age: low fertility and low mortality imply that nations are growing older globally. Current variations in age structures result from historic variations in the timing of the onset of fertility and mortality declines. Although the onset of sustained fertility decline varies from region to region, it tended to take place early in the $20^{\text {th }}$ century in Europe, while often in the second half of the $20^{\text {th }}$ century for South America, Africa and Asia (Reher 2004). In terms of mortality, the number of the world's 232 nations that experienced life expectancy below the age of 60 fell from 85 in 1980 to 45 in 2010 and is projected to decrease to only three in 2040 (United Nations 2013). As a consequence, ageing is spreading throughout the world, the main difference being the timing when the transition to a permanently older age structure is taking place. For example, Japan has an age structure that Northern Europe or Latin America will not experience until later points in time. In spite of the 
universality of ageing, there is large variation in the degree to which nations are prepared for this unprecedented fundamental demographic change. Some nations are "growing old before growing rich," experiencing population ageing without first having accumulated high levels of capital, which would allow people to have a higher quality of living in their final years of life (Lee et al. 2010).

It is important to highlight the historic demographic determinants of contemporary population trends, as these in turn may affect current age- and gender-specific labour market outcomes. In nations where the European marriage pattern prevailed, high levels of premarital celibacy and late marriage kept gross fertility at low levels, and as mortality started declining, gross fertility adjusted so that population growth stayed at low levels. In effect, net fertility did not increase much during the demographic transition - i.e. the period where populations transition from high levels of mortality and fertility to low levels of mortality and fertility, with mortality reductions leading the development before reductions in fertility set in - and population sizes increased less than in other parts of the world (United Nations 2013; Livi-Bacci 1992; McEvedy 1978; Skirbekk et al. 2015). Population growth was greater in many parts of the world as mortality declined more rapidly, and fertility - which had in the pre-demographic transition phase been at higher levels, often 7-8 children on average compared to the European case of 4-5 children on average - did not decline in time to allow for a modest increase in net reproduction.

The massive population growth that ensued presented a number of severe challenges. In terms of labour supply, these demographic changes often took place in a setting where educational systems were insufficient and labour markets poorly developed. The rapid population growth was in many nations not matched by an improvement in function of relevant institutions, such as a broadening of school coverage, improvement of labour market systems, infrastructure development and sufficient economic investments. As a consequence, opportunity costs for childbearing often remained low, as women tended to receive relatively little schooling of often mediocre quality. It is only once fertility decreases further that significant changes in the population structure take place, leading to a situation with an advantageous age composition: With a small share of the population still being old, and a decreasing share of the population being children, the working-age population constitutes the largest part of the population during this phase. This shift in the age composition entails potential benefits for economic growth that can be reaped if this large working age population is productive, i.e. if its members are healthy and educated and if economic policies conducive to economic growth are in place (Bloom et al. 2003). Hence, this so-called demographic dividend does not happen automatically when the population structure changes. Instead, these changes pose a window of opportunity that can lead to economic prosperity given the right environment.

Still, countries with younger populations are often assumed a priori to have better prospects when it comes to economic growth and per capita income - except when child-dependency ratios are high - relative to countries with older populations (Lee/Hong 2012). For example, although India and Turkey are poorer today, they are sometimes considered to have the advantage of greater long-term growth 
potential relative to China or Europe due to their younger age structures and growing population size as well as the reduced need to provide for an older, more dependent population. Anjalika Bardalai from the Economist Intelligence Unit (EIU) argues that economic growth in India will overtake China by 2018 in large part due to India's youthful age structure and population momentum, leading to more rapid growth in the working age population (Times of India 2010). The potentially deleterious effects of rapid population growth, low female economic participation and weak labour market attachment of younger age groups are usually not taken into account within traditional projections of old age burdens. Within the context of rapid growth, many demographically younger countries continue to have low education levels and younger cohorts can end up as "lost generations", with weak labour force attachment and few prospects of catching up.

Conventional ways of assessing the economic burden of ageing through an exclusively demographic approach such as the Old Age Dependency Ratio (OADR) are misleading: they are based on a set age below which people are considered to be supporters - and above which people are considered to be dependents. The purpose of the OADR is to capture the degree of dependency in a society, for example in the context of discussing the sustainability of pay-as-you-go pension systems. This approach completely ignores that country- and period-specific variation in individual characteristics can be more important than age-structures per se. Several approaches accounting for the fact that dependency is more than a question of chronological age have been suggested and applied to investigate differences in the burden of ageing between countries (Ryder 1975; Sanderson/Scherbov 2010). Spijker (2015) provides a comprehensive overview of existing alternative indicators of population ageing, grouping them into five categories into those based purely on demographic or purely economic information, both demographic and economic information, information on health and disability, and those including information on human capital. The particular comparison of dependency ratios based on employment rates with those based on income and consumption data reveals the crosscountry variation in dependency levels depending on the specific definition of who is dependent and who is not (Loichinger et al. 2014). Another example for an ageing measure that is not based on age but on specific characteristics of a population is the cognition-adjusted dependency ratio: differences in investments in education have contributed to a large variation across world regions in the physical and mental condition one experiences at older ages. Recent old age frailty measures have been based on cognitive and physical functional measures, which differ across successive cohorts (Marshall et al. 2015; Ruan et al. 2015). Further considerations refer to functional and subjective perspectives on aging that incorporate biological, social, and psychological ages, as well as societal and personal beliefs about old age (Staudinger 2015). Rising longevity may be related to changes in the timing of disease, which does not increase in parallel (Murray et al. 2015). Based on cognitive levels, the age when an individual becomes "old" can differ by more than 20 years (Skirbekk et al. 2012). Still, in spite of ample evidence that dependency purely based on age is deficient and obsolete, measures that use simple cut-off ages to define who is dependent and who is not are still widely used. 
This article aims to further promote the calculation of dependency based on economic characteristics such as employment rates instead of chronological age and to illustrate the additional insights that can be gained from this approach. We provide a broad picture of the determinants of employment decisions and show how these factors are directly related to countries' ageing prospects, pointing out differences and commonalities. For instance, in some countries an increase in female employment can more than offset the effect of a growing number of seniors - a development that would go unnoticed if demographic characteristics were the sole basis for assessing a country's ageing prospects (OECD 2006; Boeri et al. 2005). Greater economic activity levels, for instance among the elderly and women, are important for understanding how employment patterns by age and sex might affect transfers between generations, fiscal sustainability and possibly growth prospects. Importantly, factors such as wages, macro-economic conditions and union/government policies can affect employment patterns.

The contribution of this study can be summarised in the following facts: First, we present evidence for the past and the present on the similarities and differences when comparing 45 countries based on either demographic or economic dependency. There are other studies that have shown similar comparisons. However, until recently, they put scant focus on comparisons with non-European countries. Carone (2005) presents total economic dependency ratios - defined as the ratio of the total inactive population (including the $0-15$-year-olds) to those employed - for all EU countries. Contrary to his OADR forecasts, total economic dependency is projected to decline in the majority of EU25 countries until 2025 and to increase only afterwards. More recent calculations of the total economic dependency ratio for EU countries and for varying age groups can be found in a detailed report by the European Commission (2014). In order to paint a more comprehensive picture, we include more countries than previous studies did, covering up to 45 countries globally. Secondly, we explain the observed international variation in economic activity, stressing the cohort dimension in addition to presenting evidence on age- and sexspecific employment levels. There is a lack of theoretical analyses of international variation in cohort trends. Much existing evidence does not take into account, for instance, cultural variation in employment patterns, gender roles and age trajectories of employment - factors that will be decisive for whether one would benefit from a young age structure and excel in the course of the demographic transition. As we will demonstrate, cohort variation can help explain large international variations in economic dependency, where some countries experienced an earlier transition from low to high female employment decades before others. Knowing and understanding cohort trends in employment is crucial to projecting future developments because economic participation rates early in life can determine economic participation over the entire life cycle (Gregg/Tominey 2005; Blacket al.2010; Percheski 2008). If individuals entered the workforce at younger ages, they are more likely to be employed at middle and older ages, while individuals who were not employed in early adult ages are less likely to find employment later in adult life.

The remaining part of the paper is structured as follows: After defining demographic and economic dependency ratios and introducing our data sources, we give 
a detailed account of past and current levels of both ratios for our selection of countries. We then present age-, sex-and cohort-specific changes and levels of employment rates and draw on the existing literature in order to explain differences across countries and to stress the importance of paying attention to a multitude of factors when assessing the present and future dependency burden of a country.

\section{Demographic and economic dependency ratios}

The concept behind the construction of any dependency ratio is that a given population consists of two groups: those who are "contributors," and those who are "dependents". An often-used proxy for this classification is the age-specific allocation of people into those of working age who are the contributors, whereas those above (and below) working age are the dependents. Hence, the OADR is generally defined as the ratio of the number of people above working age to the number of people of working age, i.e. the ratio of the number of persons $65+$ to the number of persons aged 15 to $64 .^{1}$ This does not account for variation in retirement ages, although the United Nations (2011) alternatively uses age 70 as the "cut-off age" when one is counted as "dependent". However, this still does not take into account that many are economically inactive in their adult years, while others work beyond typical pension ages.

$$
\text { OADR (Old Age Dependecy Ratio) }=\frac{\text { number of persons } 65+}{\text { number of persons aged } 15 \text { to } 64}
$$

A more relevant measure of dependency is the notion of economic dependency. This measure takes account of the fact that not everybody of working age is actually working, just as not everyone beyond 65 is retired. The economic dependency ratio (EDR), which relates the number of non-workers to the number of workers in a given economy, provides a better representation of the share of the dependent population. $^{2}$

1 Sometimes, the lower end of the working-age population is defined at age 20, rather than 15 because in many developed countries, people do not enter the labour force until that age due to education. Since we include the BRIC countries in our analysis, where many people still enter the labour force well below the age of 20 , we take 15 as the lower cut-off age.

2 A "worker" is anyone who is considered employed according to the ILO definition of employment, i.e. anyone aged 15 and above who works for at least one hour per week (see resolution I of the Thirteenth International Conference of Labour Statisticians for details). Economic dependency has been defined in various ways in the literature, depending on what is considered the appropriate definition of activity and inactivity. What we refer to as economic dependency is based on employment and has previously been called effective economic dependency (Mattil 2006). This is the strictest definition of economic dependency; when employment is replaced with labour force participation (i.e. the sum of the employed and unemployed), the resulting ratio is a measure for potential economic dependency. 
EDR $($ Economic Dependency Ratio $)=\frac{\text { number of persons } 15+\text { who are not working }}{\text { number of persons } 15+\text { who are working }}$

The total number of persons $15+$ who are working is the result of age-specific employment rates. Age-specific employment rates are defined as the ratio between the number of employed persons and the total number of persons in the respective age group. The profile of employment rates across age shows a reversed u-shape - lower rates for young and older persons, high rates for the middle-aged. To technically account for this age-specific variation, a more elaborate representation of the EDR is

$$
\operatorname{EDR}=\frac{\sum_{15}^{65+} \mathrm{N}_{\mathrm{x}} *\left(1-\sum_{15}^{65+} \mathrm{ER}_{\mathrm{x}}\right)}{\sum_{15}^{65+} \mathrm{N}_{\mathrm{x}} * \mathrm{ER}_{\mathrm{x}}}
$$

where $N_{x}$ is the number of persons by 5-year age groups and $E R_{x}$ are the respective employment rates, sometimes also referred to as employment-to-population ratios.

In addition to age, employment rates also differ by sex, with men generally showing higher employment rates than women. However, the magnitude of these differences varies greatly between countries. To account for this variance, the formula above can be rewritten, including sex-specific rates:

$$
\mathrm{EDR}=\frac{\sum_{15}^{65+} \mathrm{N}_{\mathrm{x}, \mathrm{m}} *\left(1-\sum_{15}^{65+} \mathrm{ER}_{\mathrm{x}, \mathrm{m}}\right)+\sum_{15}^{65+} \mathrm{N}_{\mathrm{x}, \mathrm{f}} *\left(1-\sum_{15}^{65+} \mathrm{ER}_{\mathrm{x}, \mathrm{f}}\right)}{\sum_{15}^{65+} \mathrm{N}_{\mathrm{x} . \mathrm{m}} * \mathrm{ER}_{\mathrm{x} . \mathrm{m}}+\sum_{15}^{65+} \mathrm{N}_{\mathrm{x} . \mathrm{f}} * \mathrm{ER}_{\mathrm{x} . \mathrm{f}}} .
$$

Displaying economic dependency this way, it becomes clear that age- and sexspecific variation can greatly influence the eventual degree of economic dependency. For example, country A with low employment levels of older persons could have a similar economic dependency ratio as country $B$ with high employment of older workers, simply because employment of women is high in country A. As the following sections show, the potential future developments of economic dependency depend on the development of employment patterns, particularly on those of the elderly in general and of women in particular. To what extent increases in employment rates of these two groups can offset the expected reduction in total employment that most countries will face due to shrinking cohort sizes of the main age groups (20-65) depends on the individual country context.

\section{Data and methods}

We focus on both developed economies and larger industrializing countries that have shown substantial growth over recent periods: OECD members and/or EU27 countries and BRIC countries. Past and present economic dependency ratios can be 
calculated with aggregated employment data for persons aged 15+. Detailed data by sex and 5 -year age groups is used for the cohort analysis.

- Age-specific population data for the calculation of old-age dependency ratios is taken from the UN's 2008 Population Prospects (United Nations 2009). ${ }^{3}$

- Internationally comparable aggregate employment estimates for the calculation of economic dependency ratios come from the ILO's Key Indicators of the Labour Market database (KILM) (ILO 2011). Time series data starts in 1991. This data source does not contain age- and sex-specific employment rates, which explains the need for another data source as described in the next paragraph.

- Age- and sex-specific employment rates over time are compiled from the OECD (OECD 2012). The earliest data points are for 1960 with availability varying by country. In contrast to the data for calculating the EDRs - which are comparable between countries since definitions of employment are harmonised in KILM by the ILO - data from this source for the cohort development of employment are not automatically internationally comparable and also include fewer countries. The definitions vary slightly between countries (for instance, in the classification of armed forces as part of the labour force or not). However, differences are minimal and for the most part do not affect the comparability of developments over time within a country.

Repeated cross-sectional surveys are commonly used to separate age patterns from cohort trends and period effects (A/win/Krosnick 1991; André 2010; Skirbekk et al. 2013). This technique, which is applied in the present study, is used relatively often to look at employment trends of persons belonging to different cohorts.

Even though we include employment levels, and thereby go a step beyond demography, we acknowledge that the current analysis does not include information on differences in productivity resulting from variation in working hours, organisation, technology, capital or infrastructure. Furthermore, we do not take variation in skills, experience and education into account. Still, economic activity is an important measure with several important implications for fiscal sustainability, economic growth and income inequality.

\section{$4 \quad$ Analysis of demographic and economic dependency}

\subsection{Old-age and economic dependency ratios in 2008}

Figure 1 and Figure 2 compare OADRs and EDRs in 2008 for the 45 selected countries. The three countries with the highest OADR are Japan (0.33), Italy (0.31) and Germany (0.30). For every three people of working age in these countries there is about one older person. The four countries with the youngest populations (i.e. the

3 We deliberately restrict our analysis to the years before the financial crisis. Developments during the years 2009-2013 would need to be treated differently, since employment changes during that period in many countries are due to cyclical, not structural, changes. 
Fig. 1: Old-age and economic dependency ratios, OECD/EU27/BRIC countries, 2008
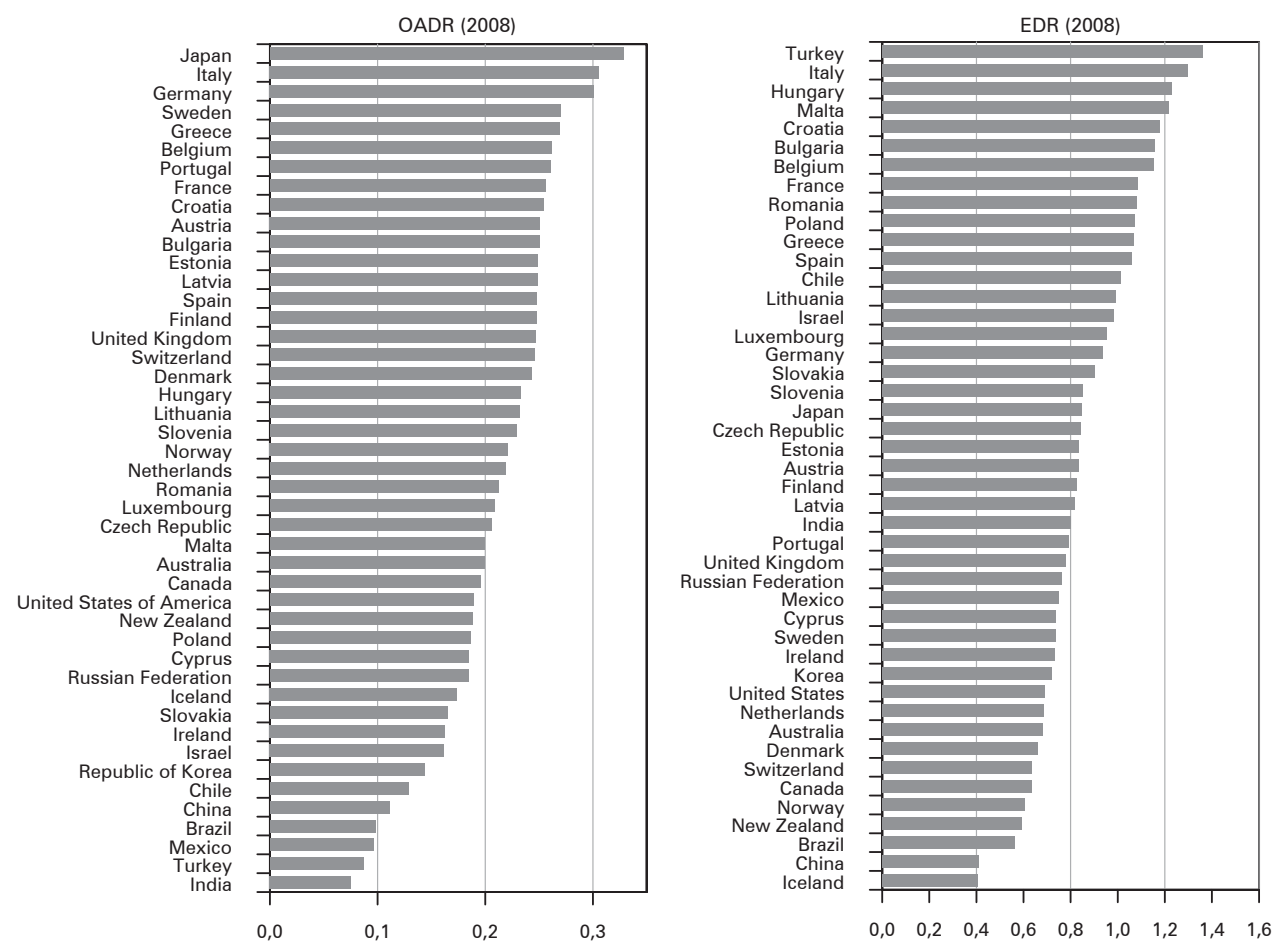

Source: Population data: United Nations 2009. Employment data: ILO estimates, KILM database, table $2 \mathrm{~A}$

lowest OADR) are India (0.08), Turkey (0.09), Mexico (0.10) and Brazil (0.10). In these countries, one older person is balanced by at least 10 people of working age. The remaining countries fall between these two groups and have an OADR between 0.1 and 0.3 .

Economic dependency is higher than demographic dependency in each of the 45 countries, and the range of economic dependency ratios is greater than the range of demographic dependency ratios (from 0.41 to 1.36 and from 0.08 to 0.33 , respectively). 13 of the 45 countries have an EDR greater than 1, which means there is more than 1 person who is not working for every person that is. The two countries with the highest EDR are Turkey (1.36) and Italy (1.3), which is remarkable because Turkey is one of the countries with the lowest OADR and Italy has one of the highest. As previously mentioned, Japan, Italy and Germany have the highest OADR and based on the comparison of these countries' demographic situations alone, one might conclude that they share a similar ageing problem. However, looking at EDR, Japan - despite being the oldest country in terms of old-age dependency - has the lowest economic dependency (0.85) of these three countries. Another noteworthy direct comparison is China and India: even though China shows higher old-age depend- 
Fig. 2: Old-age and economic dependency ratios for 45 selected countries, 2008

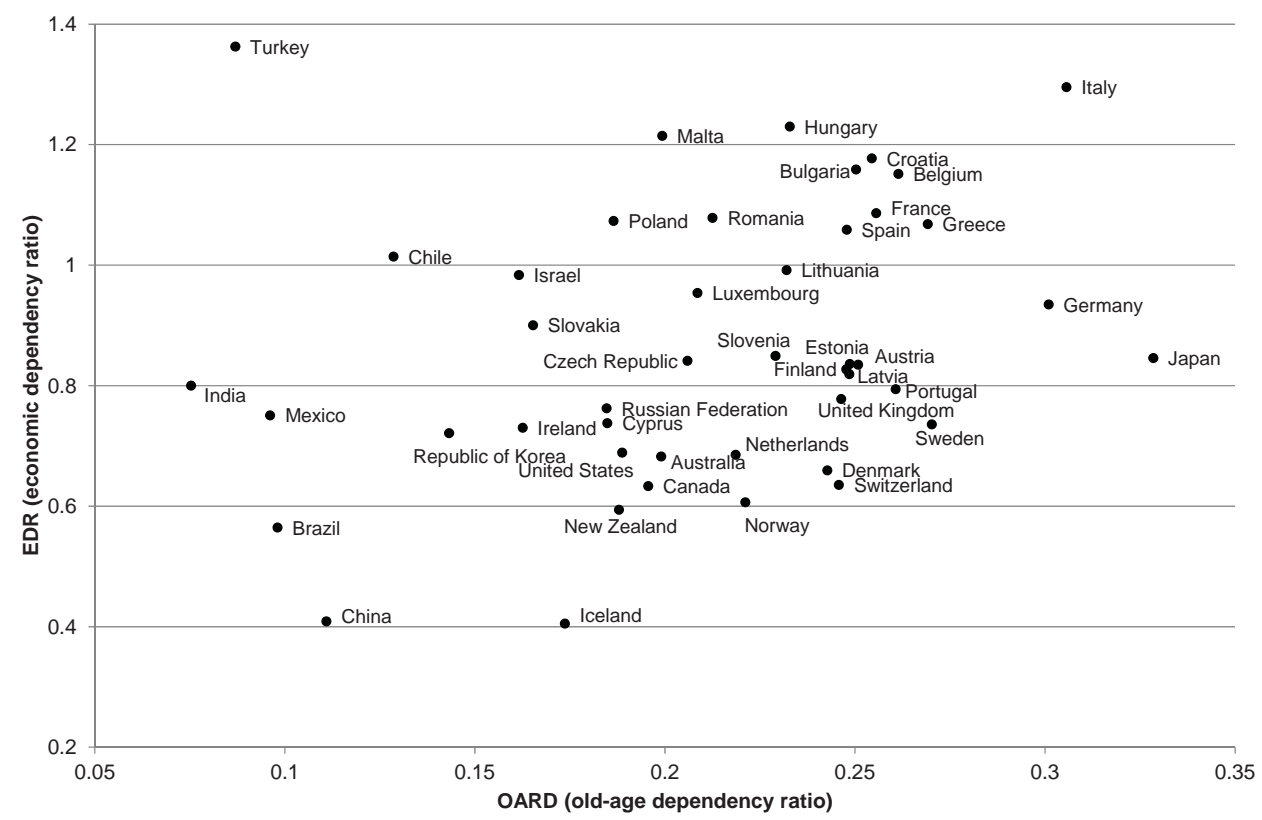

Source: Population data: United Nations 2009. Employment data: ILO estimates, KILM database, table 2A. Own calculations. Spearman's correlation coefficient: 0.34

ency than India, its economic dependency is only half that of India's in 2008 (0.41 vs. 0.80 , respectively). This discrepancy is summarised in a weak correlation between the two ratios (Spearman's correlation coefficient is only 0.34 ).

The discrepancy between demographic and economic dependency is by far the greatest in Turkey and India: the EDR/OADR ratio in these two countries is 14.66 and 9.62, respectively, which means that the OADR is not a very accurate proxy for economic dependency in these countries. The ratio of EDR to OADR is smallest for Iceland (1.33), Japan (1.57) and Switzerland (1.58), which means that in those countries, old-age dependency ratios capture economic dependency relatively well. This congruence comes from a combination of comparatively high employment rates among working age individuals and (particularly in Iceland and Japan) high employment rates observed in the $65+$ age group.

\subsection{Changes in dependency between 1991 and 2008}

In addition to the current distribution of countries by dependency, there is considerable interest regarding the change of demographic and economic indicators over time. Figure 3 depicts the absolute changes in OADR and EDR between 1991 and 2008. 
Fig. 3: Absolute changes of OADR and EDR between 1991 and 2008 for 45 selected countries

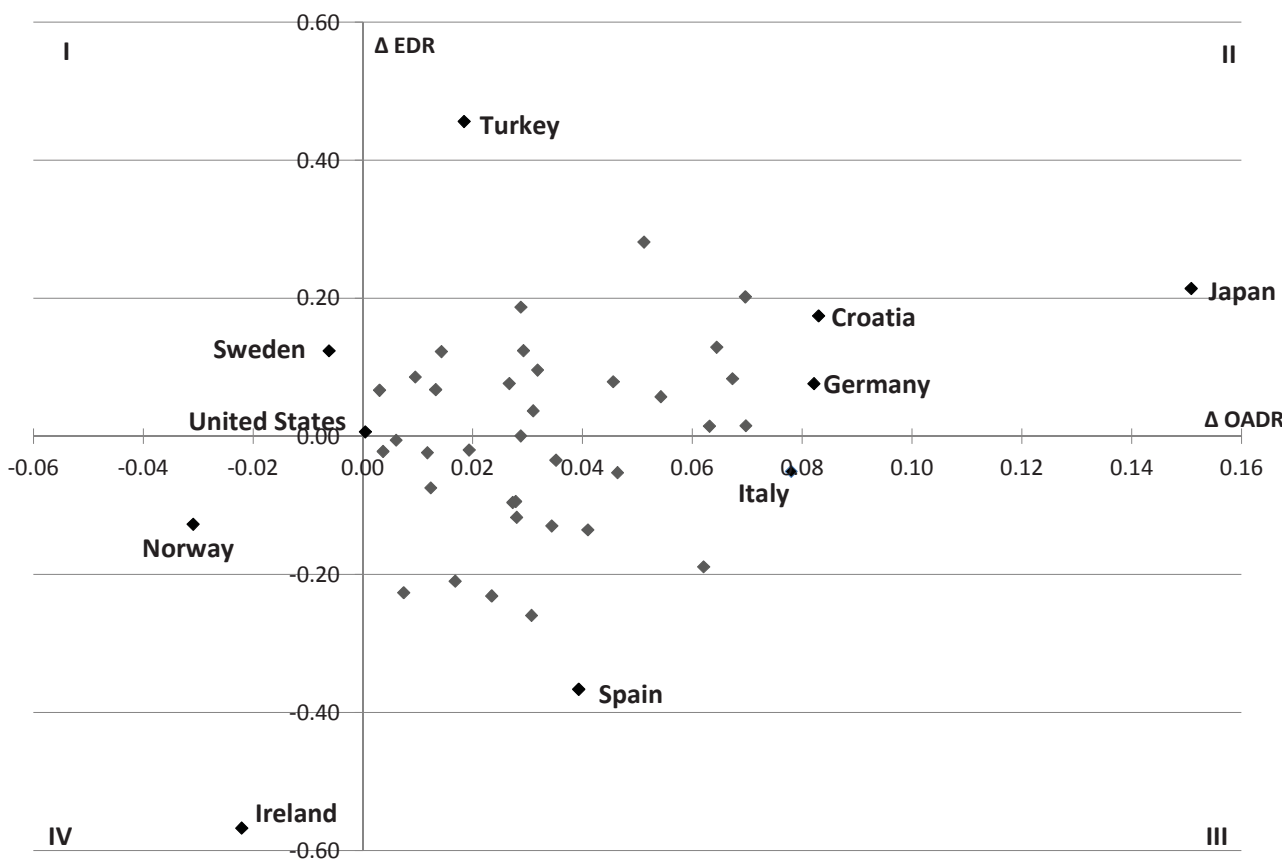

Source: Population data: United Nations 2009. Employment data: ILO estimates, KILM database, table 2A. Own calculations

The great majority of countries (42 out of 45 ) experienced an increase in their OADR in the specified time period. The largest absolute increase in old-age dependency happened in Japan (from 0.18 to 0.33 ), Croatia (from 0.18 to 0.33 ), Germany (from 0.22 to 0.30 ) and Italy (from 0.23 to 0.31 ). In three countries, old age demographic dependency actually decreased between 1991 and 2008: Sweden (from 0.28 to 0.27 ), Norway (from 0.25 to 0.22 ) and Ireland (from 0.18 to 0.16 ), which is due to the fact that the working-age population in these countries grew faster than the number of persons $65+$.

The picture is more balanced as far as the development of economic dependency is concerned: about half of the countries experienced a relative rise in EDR; the other half stayed the same or saw a decrease. The increase was by far the greatest in Turkey (from 0.91 to 1.36) and the decrease was largest for Ireland (from 1.30 to 0.73).

The four quadrants of Figure 3 illustrate the four possible combinations of increases/decreases in OADR and increases/decreases in EDR. Only two countries, namely Ireland and Norway, fall in quadrant IV, meaning that these were the only countries to see a simultaneous decrease in OARD and EDR. The majority of countries (23 out of 45 ) fall in quadrant II, which means their demographic as well as their economic dependency increased. Only slightly fewer countries though (19 out of 
Fig. 4: Trajectories of OADR and EDR from 1991 (A) to 2008 (B) for selected countries

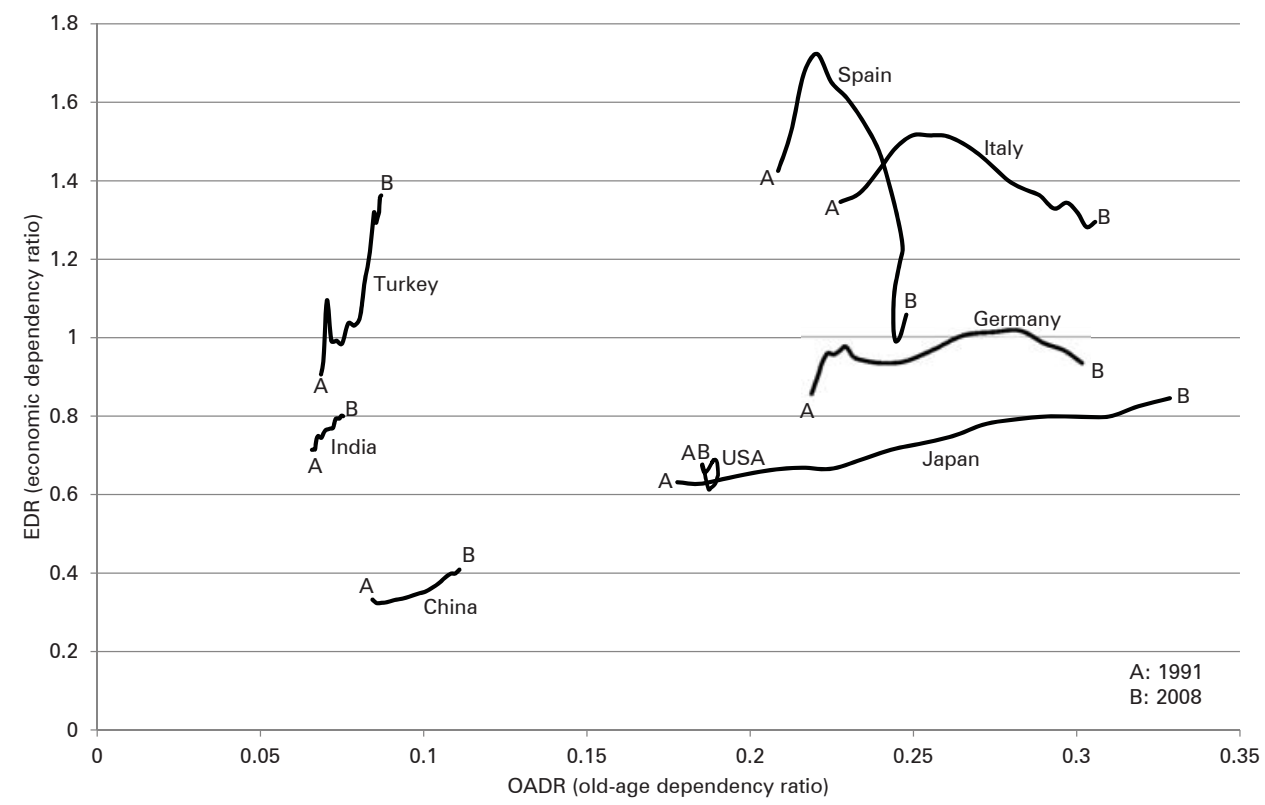

Source: Population data: United Nations 2009. Employment data: ILO estimates, KILM database, table 2A. Own calculations

45) experienced an increase in OADR, but actually saw a decrease in EDR (quadrant III), which means that even though their populations grew older, an increasing share of their adult population was employed. Figure 4 shows the trajectories of demographic and economic dependency that selected countries took between 1991 and 2008, illustrating the great variety of patterns and highlighting how the development of economic dependency is more volatile than its demographic counterpart. For example, Spain saw an initial sharp increase in economic dependency that was followed by a sharp decrease, changing direction again only shortly before 2008 , whereas Japan shows a continuous increase during the whole observation period. In the case of Germany, continued increases in female employment rates and later effective retirement ages of both men and women have entailed that even though Germany was among the countries with the largest increase in old-age dependency between 1991 and 2008, economic dependency showed a decline towards the end of the observation period.

The underlying demographic developments that explain changes in OADR over time have been well documented elsewhere (Chesnais 2000; Oeppen 2006). In the following section, we will attempt to shed light on the developments that have led to the remarkable differences in economic dependency developments. 


\section{Cohorts as determinants of employment patterns}

The development over time of economic dependency is the result of age- and sexspecific employment rates, in combination with changes in the demographic composition of a population. On the macrolevel, employment variation between countries can be explained through a myriad of factors, like business cycles, reservation wages, institutional factors, skill levels of the population, property rights, openness to trade, flexibility of financial markets, labour market flexibility, employment protection level, active labour market programs, firm establishment costs, quality and coverage of education systems and labour market regulations (Blanchard/Wolfers 2000; Freeman 2007; Nickell/Layard 1999).

Trends in sex- and age-specific employment differ widely between nations. In particular, participation of women differs more across nations, periods and successive cohorts than that of men, with women belonging to younger cohorts in nations characterised by greater gender equality, higher GDP and longer average education more likely to be part of the labour force (Charles 2011; Inglehart/Norris 2003). In general, there is a tendency that nations at earlier stages in industrial transition have relatively high employment levels and late retirement ages (OECD 2011; Kohli et al. 1991; Elu Terán 2006) and that the transition from primary to industrial and service sector jobs is related to lower employment levels and earlier retirement. However, longer education is associated with later retirement, where particularly tertiary education relates to a later age of labour market exit (Muench et al. 2009; Solem et al. 2001) and continued educational advancements in many countries are likely to lead to longer working lives. At the same time, the better educated have a longer study period, which means that they on average postpone labour market entry. Research on employment and retirement differences across cohorts highlights the importance of cohort factors in determining ages at retirement (Percheski 2008; Joshi/ Hinde 1993).

Figure 5 illustrates the developments described above by depicting changes in employment rates between 1991 and 2008 for prime aged and older men as well as women for 26 countries for which OECD data is available. ${ }^{4}$ Whereas employment levels of women increased in the great majority of countries in both age groups, increases for men are concentrated in the older age group. The largest increases in employment of 35-39-year-old women occurred in the Netherlands, Spain and Ireland. Among the older age group, men and women in New Zealand show by far the largest absolute and relative growth, whereas Turkish men and women show the most noticeable decline.

Cultural factors may also influence age- and sex-specific economic activity levels in a multitude of ways; it may impact health related behaviours (such as diet, education, family dynamics and support, physical activity levels, socialisation activity levels) that can influence health outcomes (Deaton 2009; Glaeser/Sacerdote

4 We deliberately chose an age group were participation in education and training and hence delayed entry into the labour market should no longer impact employment rates. 
Fig. 5a: Employment rates in 1991 and 2008 by age group (35-39 (two top panels)) and sex for available countries

Men 35-39

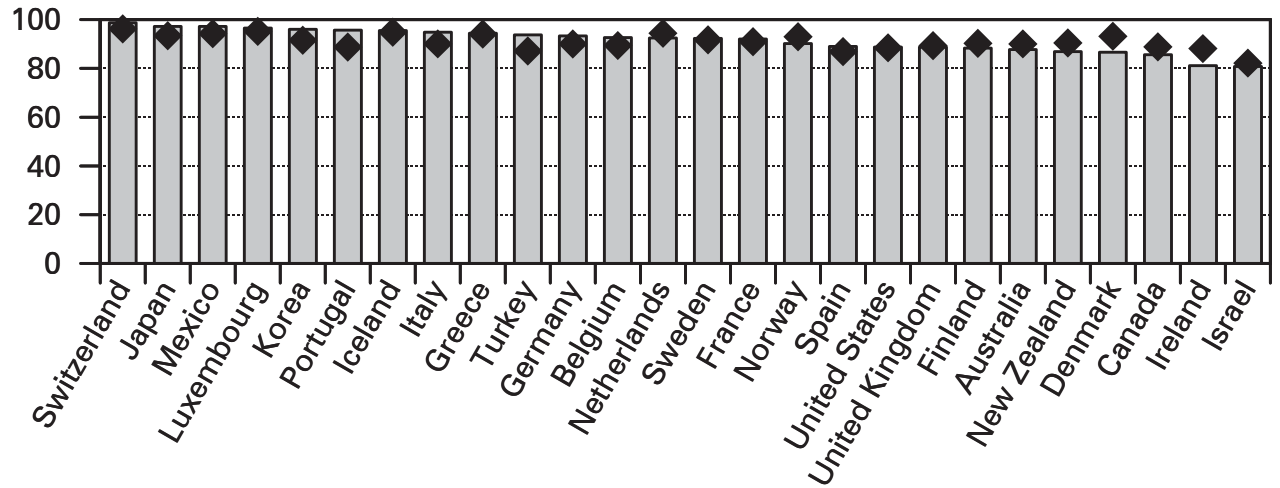

Women 35-39

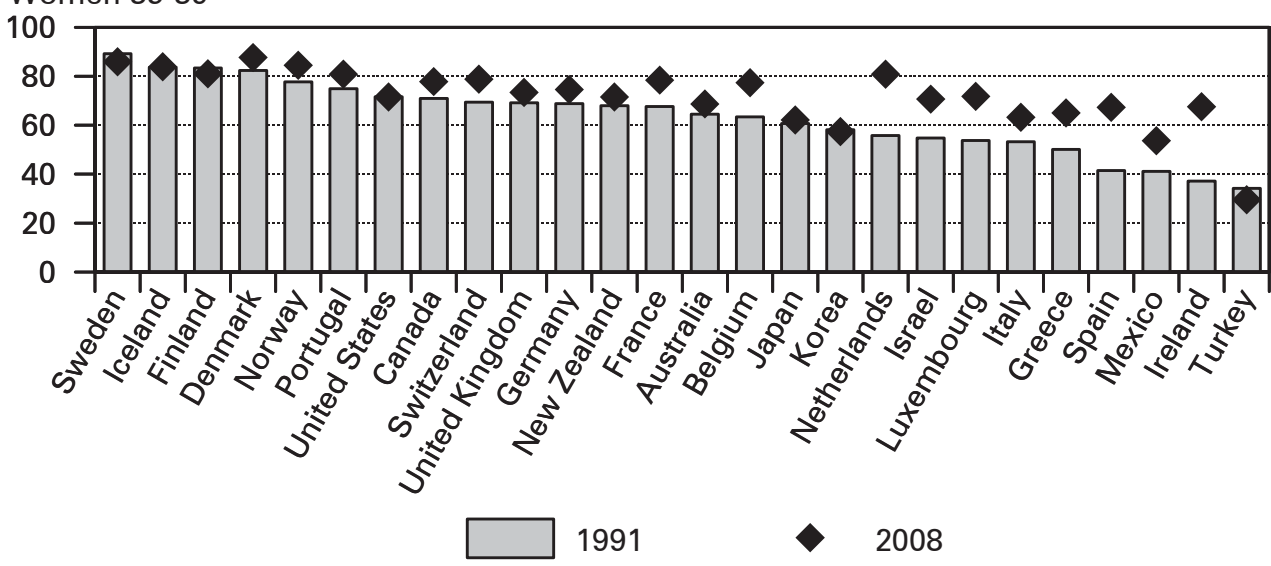

Source: employment/population ratios from OECD StatExtracts, http://stats.oecd.org/

2008; Lehrer 2004; Seguino 2011). Schooling is a key driver of both health as well as the degree of religiosity (Hungerman 2011; Javier Arias-Vazquez 2012), which could affect productivity potential and economic activity, particularly at older ages (CicireIli 2011; Kess/er/Bromet 2013). Those with a higher education stay employed longer (Dorn/Sousa-Poza 2005; Hardy 1984) and prefer to retire later (Solem et al. 2001). In effect, one may expect large variations in culture and in economic activity when it comes to population ageing. Culture and shared beliefs in a society may also impact demographic outcomes, including marital patterns and fertility behaviour, which can affect health at older ages (Grundy/Read 2015; Lehrer 2004).

Age-specific employment rates tend to follow cohort trends: individuals belonging to cohorts that experienced high or low employment levels at younger ages tend to have higher or lower employment levels throughout their lives (Plane et al. 2001; Muench et al. 2009; Carone 2005). Economic recessions at the time of labour mar- 
Fig. 5b: Employment rates in 1991 and 2008 by age group (60-64 (two bottom panels)) and sex for available countries

Men 60-64

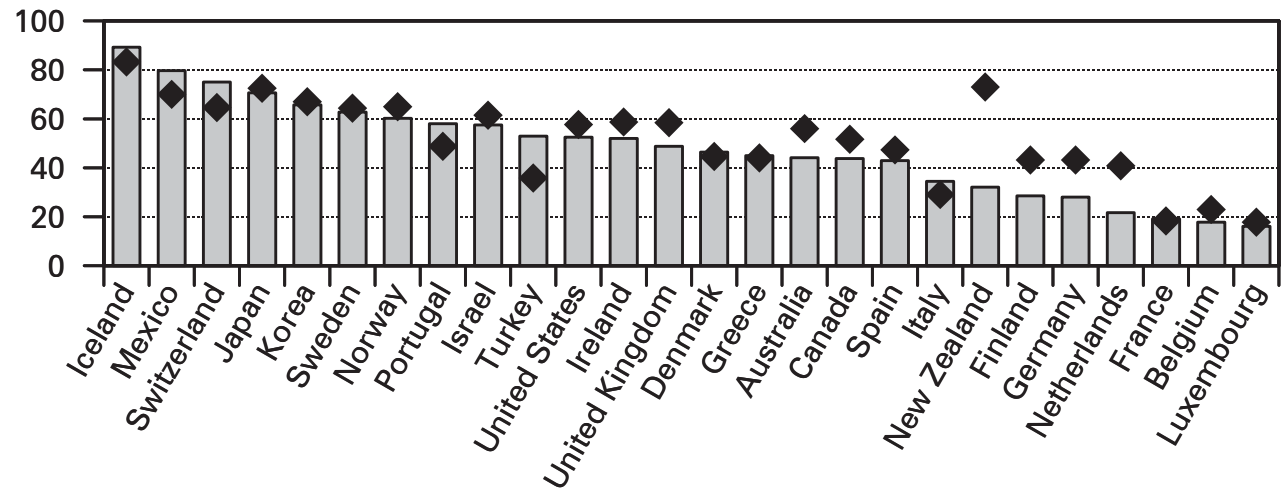

Women 60-64

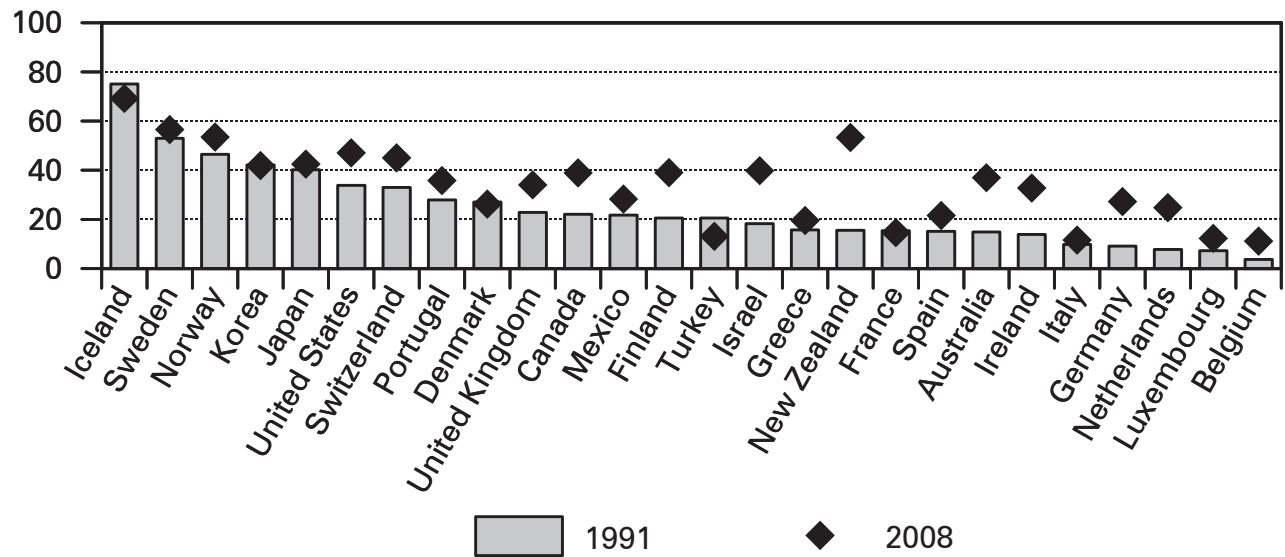

Source: employment/population ratios from OECD StatExtracts, http://stats.oecd.org/

ket entry can result in limited economic opportunities and numbers of employed for specific cohorts in some of the countries we discuss (Bentzen 2015; Travaglini 2015). For instance, cohorts born around 1950 in countries dependent on oil imports may have suffered from the oil price hike of 1973-1974 (Covi 2015).

Figure 6 depicts age- and sex-specific employment by cohorts for three example countries. The Netherlands experienced drastic increases in female employment during the last decades with women who belong to younger cohorts showing significantly higher labour market attachment than women of older cohorts. In the United States, employment developed in opposite directions for men and women (increasing employment rates for women, decreasing employment rates for men). In contrast, women as well as men in Turkey who belong to younger cohorts have had lower employment rates than older cohorts. 
Fig. 6: Employment patterns by age and sex for the Netherlands, the United States and Turkey for selected cohort groups (the years in the legend refer to cohorts' birth years)
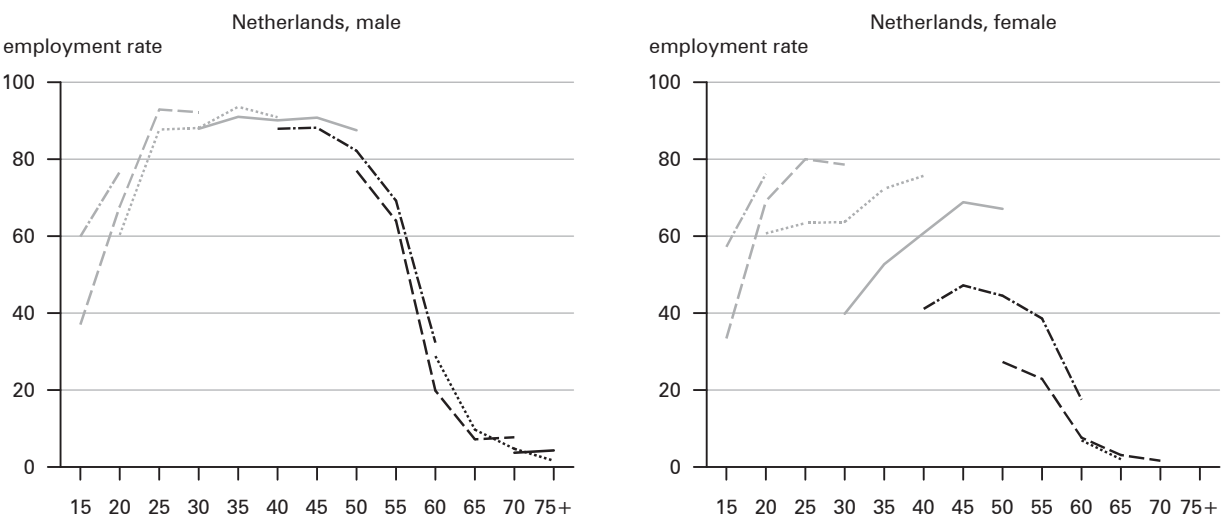

$\begin{array}{lllllllllllll}15 & 20 & 25 & 30 & 35 & 40 & 45 & 50 & 55 & 60 & 65 & 70 & 75+\end{array}$ age
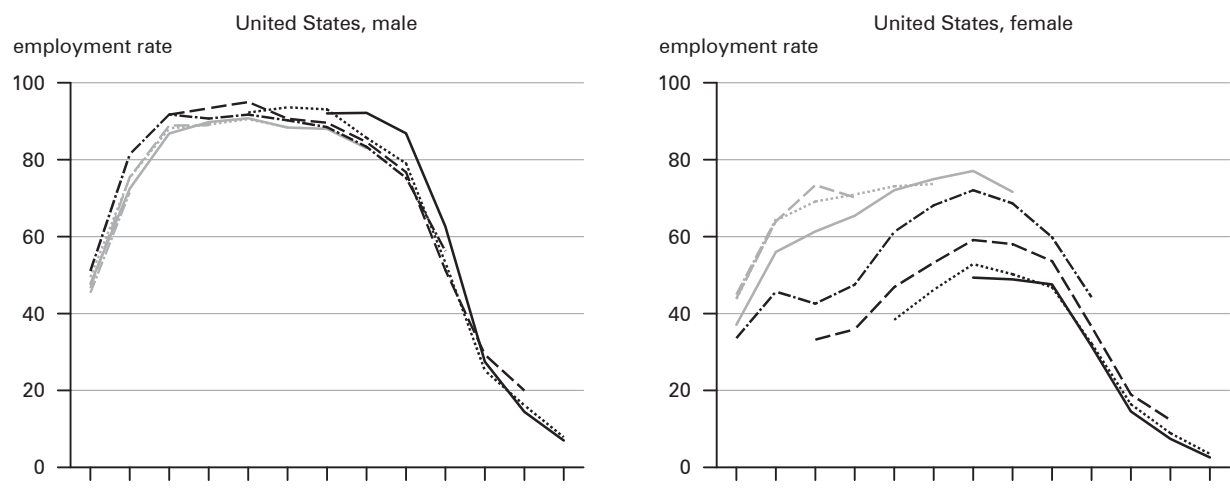

$\begin{array}{lllllllllllll}15 & 20 & 25 & 30 & 35 & 40 & 45 & 50 & 55 & 60 & 65 & 70 & 75+\end{array}$ age

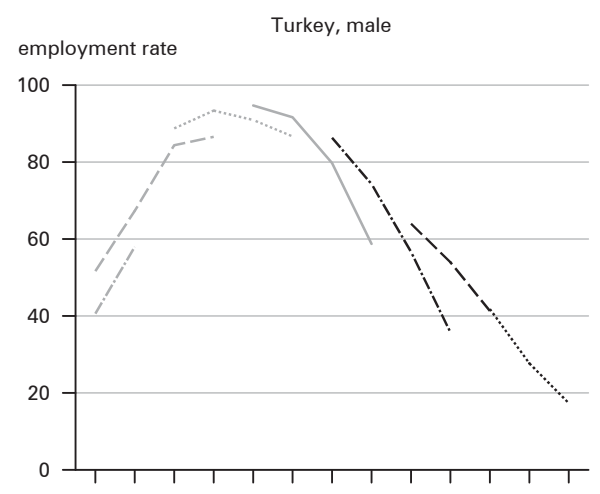

$\begin{array}{lllllllllllll}15 & 20 & 25 & 30 & 35 & 40 & 45 & 50 & 55 & 60 & 65 & 70 & 75+\end{array}$

$$
\text { age }
$$

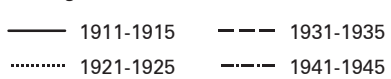

$\begin{array}{lllllllllllll}15 & 20 & 25 & 30 & 35 & 40 & 45 & 50 & 55 & 60 & 65 & 70 & 75+\end{array}$ age

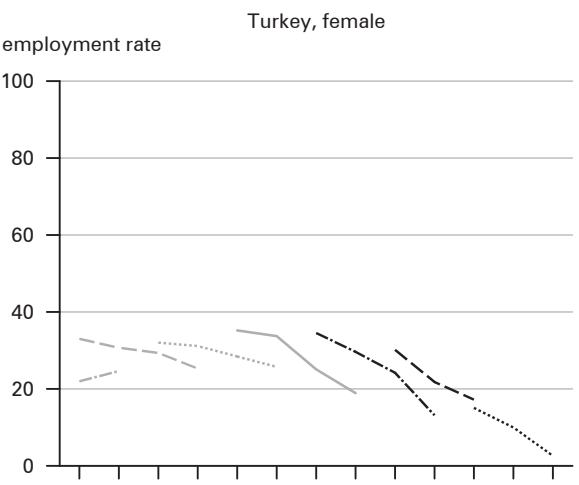

$\begin{array}{lllllllll}15 & 20 & 25 & 30 & 35 & 40 & 45 & 50 & 55\end{array}$

age

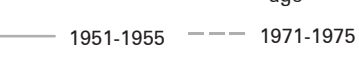

$1961-1965--\cdot-1981-1985$

Source: employment/population ratios from OECD StatExtracts, http://stats.oecd.org/ 
The Netherlands is characterised by a high level of part-time work among women, which is considered to have played an important role in the rising rate of female work participation in this nation (Figart/Golden 2013; Bosch et al. 2010). In the US, women born in the 1960s saw the strongest increases in employment compared to earlier cohorts (Boeri et al. 2005). Turkey is the outlier of this group, where economic activity continues to be below 40 percent even for women belonging to recently born cohorts, suggesting that rapid economic growth has not translated into greater economic activity for large segments of the population. The Turkish situation appears to reflect increased development in economic activity due to economic necessity that is subsequently reduced due to cultural reasons that constrain the growth of female employment. In this case, the effects of modernisation may be smaller than those of culture, implying that most Turkish women do not have paid work (Gündüz-Hoşgör/Smits 2008). Another explanation for low overall levels of female economic activity in Turkey is the continued urbanisation and decline of employment in subsistence agriculture (World Bank 2009). It is also important to note that income from work is more important in Turkey than in other OECD nations for determining poverty (Şeker/Dayıoğlu 2014), which in turn may reduce costly investments in skills and education for families that are relatively poor, maintaining low employment rates.

Gender roles, including attitudes towards work, vary widely, also within Europe and have been found to affect labour force participation and economic activity levels (Camussi 2013; Gökse/ 2013). Cohort differences in attitudes could explain cohort differences in work patterns for men and women (Parry/Urwin 2011). In some countries, such as Japan and several European countries, attitudes towards gender equality are much more positive among younger cohorts, which could suggest a much more positive effect for these nations (Norris/Inglehart 2011; Pampel 2011; Skirbekk et al. 2015).

\section{Conclusion}

Ageing has led to widespread concerns about rising dependency ratios and fears of negative effects on economic growth and sustainability of social security (OECD 2006). However, the economic behaviours, characteristics and abilities that vary by country and cohort are often more important than the demographic age structure per se. Our analysis of 45 countries reiterates the discrepancy between old age dependency ratios and economic dependency ratios. Nations that have experienced a lower old age burden from a demographic viewpoint are often nations that have low economic activity in their working age population - many of whom face a greater economic dependency burden in spite of their young age structure.

For instance, even if Turkey and India have the second lowest old age dependency ratio in our 45-nation sample, they have the highest economic dependency ratio. In contrast, nations such as Sweden or Norway, which are relatively old, have a much more favorable economic dependency ratio. This suggests that countries with cultural and economic environments conducive to the inclusion of women in 
the labour market are in a more advantageous situation when it comes to population ageing. Furthermore, nations that manage to maintain longer working lives for seniors and higher levels of employment among the young are in a better position to cope with demographic change.

The contextual dimension of ageing has not been sufficiently discussed, and this study provides an example that may provide insights into some of the dynamics associated with cohort and cross-country variation in labour force participation by sex. One potentially important dimension of economic activity that has seldom been factored in when it comes to macro level variation in ageing is culture. Although ageing takes place everywhere and demographic age distributions in the longer term are likely to partially converge between countries, there is greater uncertainty in the extent to which cultural traits converge and whether these traits will affect behaviours relevant to how well nations age, including economic activity. Such non-economic factors influencing economic outcomes seem to have received insufficient attention in the general literature on population ageing. National cultures and norms may influence the ages for entering and exiting the workforce and attitudes to work in life. Whether women enter the labour force, whether women continue to work after childbearing years and overall levels of economic activity are all influenced by ageing. In effect, culture can be determining how nations experience population ageing. For example, cultural factors may have a decisive role in countries such as Turkey, which is the nation with the lowest female employment level in our sample, and also in many Asian countries. Given that employment patterns follow cohort trends, changes in age-specific employment levels occur slowly and current levels will determine future levels at least for the medium term. How employment, particularly of older people and of women, will develop depends on a multitude of factors. Attitudes towards older workers, particularly older people's productivity and their work potential could be important in determining future work participation - more positive attitudes could potentially translate into later retirement (Remery et al. 2003; Conen et al. 2012). One study based on an analysis of 11 nations from the European Social Survey found that older people's participation in paid and volunteer work is related to perceptions of older people's competence independent of older people's actual competence (Bowen/Skirbekk 2013). Later retirement could make it easier to cope with demographic change as it could raise the ratio between the economically active and the economically inactive. Although development is universal, in many nations attitudes towards women in the labour market are still negative (/nglehart/ Baker 2000; Lueck 2005). This can be increasingly important following demographic change, as more individuals will enter ages where economic activity levels tend to be low and if women would increase their economic activity, this could alleviate the impacts of population ageing to a significant extent. Cultural variation in the understanding of the ages one should enter and leave the workforce, whether working is seen as positive - for instance through self-realisation or a service to society - or whether women should be economically active after having children can be highly important for determining lifetime outcomes.

In some countries, for example in Greece and Spain, the financial crisis in Europe has led to unprecedented levels of unemployment among the young generation. 
What this generation's employment history will look like as they grow older remains to be seen. Since experience in other countries and contexts has shown that low levels of employment at young ages can translate into lower than usual activity levels during the whole life course, events like the financial crisis can directly affect economic dependency for decades to come. This again stresses the importance of moving away from measuring dependency based on age structure and to instead include the economic dimension and to pay particular attention to cohort developments.

Employment opportunities and outcomes do correlate with educational attainment. A natural extension to our paper could be the addition of human capital in considerations of future levels of economic dependency. The effect of changes in the educational attainment structure along cohort lines can have positive as well as negative consequences and thus alleviate or aggravate population ageing, depending on the size of different effects. On the one hand, expansions in the educational attainment level of European workers entails higher human capital among the future workforce compared to the present situation, exerting a potential positive effect on labour productivity and economic growth (Loichinger 2015; Crespo Cuaresma et al. 2016). On the other hand, weighting people according to their level of educational attainment illustrates how upward changes in the educational attainment level of the future elderly may put additional pressure on pension systems, as exemplified in the case of Italy (Philipov et al. 2014). Hence, the construction of economic dependency ratios for a wide range of countries that do take changes in human capital into account could potentially capture these kinds of effects and provide a more complete picture of future global dependency.

\section{Acknowledgements}

Partial funding for this work was made possible by the "Wittgenstein Award" of the Austrian Science Fund (FWF): Z171-G11. The authors would like to express their thanks to three anonymous reviewers for their valuable comments and suggestions.

\section{References}

Alwin, Duane F.; Krosnick, Jon A. 1991: Aging, Cohorts and Stability of Socio-Political Orientations over the Life Span. In: American Journal of Sociology 97: 169-95.

André, Malin 2010: Cohort Differences in Personality in Middle-Aged Women during a 36-Year Period: Results from the Population Study of Women in Gothenburg. In: Scandinavian Journal of Public Health 38,5: 457-64 [doi: 10.1177/1403494810371247].

Bentzen, Jan 2015: Comparing Data Sources of Real GDP in Purchasing Power Parities. In: Applied Economics Letters 22,16:1303-1308 [doi: 10.1080/13504851.2015.1026576].

Black, David; Tseng, Yi-Ping; Wilkins, Roger 2010: The Decline in Male Employment in Australia: A Cohort Analysis. In: Australian Economic Papers 49,3: 180-199 [doi: 10.1111/j.1467-8454.2010.00395.x]. 
Blanchard, Olivier; Wolfers, Justin 2000: The Role of Shocks and Institutions in the Rise of European Unemployment: The Aggregate Evidence. In: The Economic Journal 110,462: 1-33 [doi: 10.1111/1468-0297.00518].

Bloom, David; Canning, David; Sevilla, Jaypee 2003: The demographic dividend: A new perspective on the economic consequences of population change. Rand Corporation. [doi: 10.2307/20033592].

Boeri, Tito; Del Boca, Daniela; Pissarides, Christopher A. 2005: Women at Work: An Economic Perspective. OUP Catalogue. Oxford University Press [doi: 10.1111/j.14678543.2010.00781_9].

Bosch, Nicole; Deelen, Anja; Euwals, Rob 2010: Is Part-Time Employment Here to Stay? Working Hours of Dutch Women over Successive Generations. In: LABOUR 24,1: 3554 [doi: 10.1111/j.1467-9914.2010.00470.x].

Bowen, Catherine E.; Skirbekk, Vegard 2013: National Stereotypes of Older People's Competence Are Related to Older Adults' Participation in Paid and Volunteer Work. In: The Journals of Gerontology Series B: Psychological Sciences and Social Sciences 68,6: 974-983 [doi: 10.1093/geronb/gbt101].

Camussi, Silvia Annamaria 2013: Female Labour Market Participation and Cultural Variables. In: Bank of Italy Occasional Paper 178 [doi: 10.2139/ssrn.2297874].

Carone, Guiseppe 2005: Long-Term Labour Force Projections for the 25 EU Member States: A Set of Data for Assessing the Economic Impact of Ageing. Brussels: European Commission [doi: 10.2139/ssrn.871086].

Charles, Maria 2011: A World of Difference: International Trends in Women's Economic Status. In: Annual Review of Sociology 37,1: 355-371 [doi: 10.1146/annurev. soc.012809.102548].

Chesnais, Jean-Claude 2000: Determinants of below-replacement fertility. In: Below Replacement Fertility. Population Bulletin of the United Nations, Special Issue Nos. 40-41. New York: United Nations: 126-136.

Cicirelli, Victor G. 2011: Elders' Attitudes toward Extending the Healthy Life Span. In: Journal of Aging Studies 25,2:84-93 [doi: 10.1016/j.jaging.2010.08.011].

Conen, Wieteke S.; van Dalen, Hendrik P.; Henkens, Kène 2012: Ageing and Employers' Perceptions of Labour Costs and Productivity: A Survey among European Employers. In: International Journal of Manpower 33,6: 629-647 [doi: 10.1108/01437721211261796].

Covi, Giovanni 2015: Puzzling out the First Oil Shock. History, Politics and the Macroeconomy in a Forty-Year Retrospective. In: History of Economic Thought and Policy 2015,2: 57-91 [doi: 10.3280/SPE2015-002004].

Crespo Cuaresma, Jesus; Loichinger, Elke; Vincelette, Gallina A. 2016: Aging and income convergence in Europe: A survey of the literature and insights from a demographic projection exercise. In: Economic Systems 40,1: 4-17 [doi: 10.1016/j.ecosys.2015.07.003].

Deaton, Angus S. 2009: Aging, Religion, and Health. In: NBER Working Paper No. 15271. [doi: 10.3386/w15271].

Dorn, David; Sousa-Poza, Alfonso 2005: The Determinants of Early Retirement in Switzerland. In: Swiss Journal of Economics and Statistics (SJES) 141,II: 247-283 [doi: 10.5167/uzh-99445].

European Commission 2014: The 2015 Ageing Report. Underlying Assumptions and Projection Methodologies. In: European Economy Series 8/2014 [doi: 10.2765/76255 ]. 
Elu Terán, Alexander 2006: The Work of Spanish Older Men: A Quantitative Analysis Based on Census Data, 1900-70. In: Economic History Society, Annual Conference 2006. Pittsburgh: History Association Press.

Figart, Deborah M.; Golden, Lonnie 2013: Working Time: International Trends, Theory and Policy Perspectives. Routledge.

Freeman, Richard 2007: America Works: The Exceptional Labor Market. Russell Sage Foundation.

Glaeser, Edward L.; Sacerdote, Bruce I. 2008: Education and Religion. In: Journal of Human Capital 2,2: 188-215 [doi: 10.1086/590413].

Göksel, Idil 2013: Female Labor Force Participation in Turkey: The Role of Conservatism. In: Women's Studies International Forum 41: Elsevier: 45-54 [doi: 10.1016/j. wsif.2013.04.006].

Gregg, Paul; Tominey, Emma 2005: The Wage Scar from Male Youth Unemployment. In: Labour Economics 12,4: 487-509 [doi: 10.1016/j.labeco.2005.05.004].

Grundy, Emily; Read, Sanna 2015: Pathways from Fertility History to Later Life Health: Results from Analyses of the English Study of Ageing. In: Demographic Research 32,4: 1-54 [doi: 10.4054/DemRes.2015.32.4].

Gündüz-Hoşgör, Ayşe; Smits, Jeroen 2008: Variation in Labor Market Participation of Married Women in Turkey. In: Women's Studies International Forum 31,2: 104-117 [doi: 10.1016/j.wsif.2008.03.003].

Hardy, Melissa A. 1984: Effects of Education on Retirement among White Male Wageand-Salary Workers. In: Sociology of Education 57,2:84-98 [doi: 10.2307/2112631].

Hungerman, Danie/ M. 2011: The Effect of Education on Religion: Evidence from Compulsory Schooling Laws. National Bureau of Economic Research Working Paper No. 16973. Cambridge, MA [doi: 10.3386/w16973].

ILO 2011: Key Indicators of the Labour Market (KILM), A Multi-Functional Research Tool of the ILO Consisting of Country-Level Data on 18 Key Indicators of the Labour Market from 1980 to the Latest Available Year. Geneva: Economic and Labour Market Analysis Department.

Inglehart, Ronald; Baker, Wayne E. 2000: Modernization, Cultural Change and the Persistence of Traditional Values. In: American Sociological Review 65,1: 19-51 [doi: 10.2307/2657288].

Inglehart, Ronald; Norris, Pippa 2003: Rising Tide: Gender Equality and Cultural Change Around the World. Cambridge: Cambridge University Press.

Javier Arias-Vazquez, F. 2012: A Note on the Effect of Education on Religiosity. In: Economics Letters 117,3: 895-897 [doi: 10.1016/j.econlet.2012.07.005].

Joshi, Heather; Hinde, P. R. Andrew 1993: Employment after Childbearing in Post-War Britain: Cohort-Study Evidence on Contrasts within and across Generations. In: European Sociological Review 9,3: 203-227.

Kessler, Ronald C.; Bromet, Evelyn J. 2013: The Epidemiology of Depression across Cultures. In: Annual review of public health 34: 119-138 [doi: 10.1146/annurev-publhealth-031912-114409].

Kohli, Martin et al. (Eds.) 1991: Time for Retirement: Comparative Studies of Early Exit from the Labor Force. Cambridge, NY: Cambridge University Press.

Lee, Jong-Wha; Hong, Kiseok 2012: Economic Growth in Asia: Determinants and Prospects. In: Japan and the World Economy 24,2: 101-113 [doi: 10.1016/j.japwor.2012.01.005]. 
Lee, Ronald; Mason, Andrew; Cotlear, Danie/ 2010: Some Economic Consequences of Global Aging: A Discussion Note for the World Bank. World Bank. Washington, DC. World Bank.

Lehrer, Evelyn L. 2004: Religion as a Determinant of Economic and Demographic Behavior in the United States. In: Population and Development Review 30,4: 707-726 [doi: 10.1111/j.1728-4457.2004.00038.x].

Livi-Bacci, Massimo 1992: A Concise History of World Population. Cambridge, MA: Blackwell.

Loichinger, Elke 2015: Labor Force Projections up to 2053 for 26 EU countries by Age, Sex, and Highest Level of Educational Attainment. In: Demographic Research 32,15: 443-486 [doi: 10.4054/DemRes.2015.32.15].

Loichinger, Elke et al. 2014: Economic dependency ratios: Present situation and future scenarios. WWWForEurope Working Paper No. 74.

Lueck, Detlev 2005: Cross-National Comparison of Gender Role Attitudes and Their Impact on Women's Life Course. Working Paper 67. Bamberg, Germany: Otto-Friedrich University of Bamberg.

Mattil, Birgit 2006: Pension Systems: Sustainability and Distributional Effects in Germany and the United Kingdom. Springer [doi: 10.1007/3-7908-1676-0].

Marshall, Alan et al. 2015: Cohort Differences in the Levels and Trajectories of Frailty among Older People in England. In: Journal of epidemiology and community health 69,4: 316-321 [doi: 10.1136/jech-2014-2046559].

McEvedy, Colin 1978: Atlas of World Population History. Harmondsworth: Penguin Books.

Muench, Claudia; Sweder, Van Wijnbergen; Lejour, Arjan 2009: Education and Labor Market Activity of Women: An Age-Group Specific Empirical Analysis. SSRN Scholarly Paper ID 1578307. Rochester, NY: Social Science Research Network [doi: 10.2139/ ssrn.1505279].

Murray, Christopher J. L. et al. 2012: Disability-Adjusted Life Years (DALYs) for 291 Diseases and Injuries in 21 Regions, 1990-2010: A Systematic Analysis for the Global Burden of Disease Study 2010. In: The Lancet 380, (9859): 2197-2223 [doi: 10.1016/ S0140-6736(12)61689-4].

Murray, Christopher J.L. et al. 2015: Global, Regional, and National Disability-Adjusted Life Years (Dalys) for 306 Diseases and Injuries and Healthy Life Expectancy (Hale) for 188 Countries, 1990-2013: Quantifying the Epidemiological Transition. In: The Lancet 386, (10009): 2145-2191 [doi: 10.1016/S0140-6736(15)61340-X].

Nickell, Stephen; Layard, Richard 1999: Labor Market Institutions and Economic Performance. In: Ashenfelter, Orley C.; Card, David (Eds.): Handbook of Labor Economics, Volume 3, Part C. Elsevier: 3029-3084.

Norris, Pippa; Inglehart, Ronald 2011: Sacred and Secular: Religion and Politics Worldwide. Cambridge University Press.

OECD 2006: Live Longer, Work Longer. Ageing and Employment Policies. Paris: Organisation for Economic Cooperation and Development [doi : 10.1787/9789264035881-en].

OECD 2011: Ageing and Employment Policies - Statistics on Average Effective Age of Retirement. Paris: Organisation for Economic Co-operation and Development.

OECD 2012: StatExtracts Database. Paris: Organisation for Economic Co-operation and Development. 
Oeppen, Jim 2006: Life Expectancy Convergence among Nations since 1820: Separating the Effects of Technology and Income. In: Bengtsson, Tommy (Ed.): Perspectives on Mortality Forecasting-III. The Linear Rise in Life Expectancy: History and Prospects. Försäkringskassan: Swedish Social Insurance Agency: 55-82.

Pampel, Fred 2011: Cohort Changes in the Socio-Demographic Determinants of Gender Egalitarianism. In: Social Forces 89,3: 961-982 [doi: 10.1353/sof.2011.0011].

Parry, Emma; Urwin, Peter 2011: Generational Differences in Work Values: A Review of Theory and Evidence. In: International Journal of Management Reviews 13,1: 79-96 [doi: 10.1111/j.1468-2370.2010.00285.x].

Percheski, Christine 2008: Opting Out? Cohort Differences in Professional Women's Employment Rates from 1960-2005. In: American Sociological Review 73,3: 497-513 [doi: 10.1177/000312240807300307].

Philipov, Dimiter; Goujon, Anne; Di Giulio, Paola 2014: Ageing dynamics of a humancapital-specific population: A demographic perspective. In: Demographic Research 31,44: 1311-1336 [doi: 10.4054/DemRes.2014.31.44].

Plane, Mathieu et al. 2001: Labour Supply and Labour Force Participation in Europe : A Discussion of Some Recent Developments and Projections. 1049. Kieler Arbeitspapiere.

Reher, David S. 2004: The demographic transition revisited as a global process. In: Population, Space and Place 10: 19-41 [doi: 10.1002/psp.313].

Remery, Chantal et al. 2003: Managing an Aging Workforce and a Tight Labor Market: Views Held by Dutch Employers. In: Population Research and Policy Review 22,1: 21 40 [doi: 10.1023/A:1023543307473].

Ruan, Qingwei et al. 2015: Cognitive Frailty, a Novel Target for the Prevention of Elderly Dependency. In: Ageing research reviews 20: 1-10 [doi: 10.1016/j.arr.2014.12.004].

Ryder, Norman B. 1975: Notes on stationary populations. In: Population Index 41: 3-28 [doi:10.2307/2734140].

Sanderson, Warren C.; Scherbov, Sergei 2010: Remeasuring aging. In: Science 329: 1287-1288 [doi:10.1126/science.1193647].

Seguino, Stephanie 2011: Help or Hindrance? Religion's Impact on Gender Inequality in Attitudes and Outcomes. In: World Development 39,8: 1308-1321 [doi: 10.1016/j. worlddev.2010.12.004].

Şeker, Sırma Demir; Dayıoğlu, Meltem 2014: Poverty Dynamics in Turkey. In: Review of Income and Wealth 61,3: 477-493 [doi: 10.1111/roiw.12112].

Skirbekk, Vegard; Matsukura, Rikiya; Ogawa, Naohiro 2015: What Are the Prospects for Continued Low Fertility in Japan? In: Ogawa, Naohiro; Shah, Iqbal H. (Eds.): Low Fertility and Reproductive Health in East Asia. Springer: 75-100 [doi: 10.1007/978-94017-9226-4_5].

Skirbekk, Vegard; Stonawski, Marcin; Alfani, Guido 2015: Consequences of a universal European demographic transition on regional and global population distributions. In: Technological Forecasting and Social Change 98: 271-289 [doi: 10.1016/j.techfore.2015.05.003].

Skirbekk, Vegard; Loichinger, Elke; Weber, Daniela 2012: Variation in Cognitive Functioning as a Refined Approach to Comparing Aging across Countries. In: Proceedings of the National Academy of Sciences 109,3: 770-774 [doi: 10.1073/pnas.1112173109].

Skirbekk, Vegard et al. 2013: The Flynn Effect and Population Aging. In: Intelligence 41,3: 169-177 [doi: 10.1016/j.intell.2013.02.001]. 
Solem, Per Erik; Mykletun, Reidar J.; Mykletun, Arnstein 2001: Early Exit and Motivation to Work after 62. Paper presented at The 17th Congress of the International Association of Gerontology. Vancouver, Canada, July, 1-6, 2001.

Spijker, Jeroen. 2015: Alternative Indicators of Population Ageing: An Inventory. VID Working Papers 4/2015, Vienna.

Staudinger, Ursula M. 2015: Images of Aging: Outside and Inside Perspectives. In: Annual review of gerontology and geriatrics 35,1: 187-209 [doi: 10.1891/0198-8794.35.187].

Times of India 2010: India to Overtake China in Growth by 2018: EIU. March 17. Times of India: Mumbai.

Travaglini, Giuseppe 2015: The Productivity Gap among European Countries. Working Papers Series in Economics, Mathematics and Statistics Urbino University (IT).

United Nations 2009: World Population Prospects: The 2008 Revision. New York: United Nations, Department of Economic and Social Affairs, Population Division.

United Nations 2011: World Population Prospects, the 2010 Revision: Frequently Asked Questions (updated 3 April 2011). New York, NY: United Nations Department of Economic and Social Affairs, Population Division.

United Nations 2013: World Population Prospects: The 2012 Revision. New York: United Nations, Department of Economic and Social Affairs, Population Division.

World Bank 2009: Female Labor Force Participation in Turkey: Trends, Determinants and Policy Framework. 48508-TR. Washington, D.C.: World Bank.

Dr. Elke Loichinger ( $₫)$. College of Population Studies, Chulalongkorn University, Bangkok.

Research Institute Human Capital and Development, Vienna University of Economics and Business.

E-mail: Elke.L@chula.ac.th

URL: https://www.wu.ac.at/index.php?id=20299

Vegard Skirbekk. Columbia Aging Center, Columbia University, New York.

Norwegian Institute of Public Health, Oslo.

E-mail: Vegard.Skirbekk@fhi.no

URL: http://aging.columbia.edu/vegard-skirbekk-phd 


\section{Comparative Population Studies}

WWW.comparativepopulationstudies.de

ISSN: 1869-8980 (Print) - 1869-8999 (Internet)

Published by

Prof. Dr. Norbert F. Schneider

Federal Institute for Population Research

D-65180 Wiesbaden / Germany

\section{(cc) BY-SA}

2016

\section{Managing Editor}

Frank Swiaczny

\section{Assistant Managing Editor}

Katrin Schiefer

\section{Copy Editor}

(Selected Articles in German)

Dr. Evelyn Grünheid

\section{Layout}

Beatriz Feiler-Fuchs

E-mail:cpos@bib.bund.de

\section{Scientific Advisory Board}

Paul Gans (Mannheim)

Karsten Hank (Köln)

Johannes Huinink (Bremen)

Michaela Kreyenfeld (Rostock)

Marc Luy (Wien)

Notburga Ott (Bochum)

Peter Preisendörfer (Mainz)

Nikola Sander (Groningen)

Zsolt Spéder (Budapest)

\section{Board of Reviewers}

Martin Abraham (Erlangen)

Laura Bernardi (Lausanne)

Hansjörg Bucher (Bonn)

Claudia Diehl (Konstanz)

Andreas Diekmann (Zürich)

Gabriele Doblhammer-Reiter (Rostock)

Jürgen Dorbritz (Wiesbaden)

Anette Eva Fasang (Berlin)

E.-Jürgen Flöthmann (Bielefeld)

Alexia Fürnkranz-Prskawetz (Wien)

Beat Fux (Salzburg)

Joshua Goldstein (Berkeley)

Sonja Haug (Regensburg)

Hill Kulu (Liverpool)

Aart C. Liefbroer (Den Haag)

Kurt Lüscher (Konstanz)

Emma Lundholm (Umeå)

Nadja Milewski (Rostock)

Dimiter Philipov (Wien)

Roland Rau (Rostock)

Tomáš Sobotka (Wien) Jeroen Spijker (Barcelona)

Olivier Thévenon (Paris)

Helga de Valk (Brussel)

Heike Trappe (Rostock)

Michael Wagner (Köln) 